Institute of $\mathbf{F}_{\text {ood and }} \mathbf{A}$ gricultural $\mathbf{S}_{\text {ciences }}$

\title{
Alternatives of Low Cost Soil Moisture Monitoring Devices for Vegetable Production in South Miami-Dade County 1
}

Rafael Muñoz-Carpena, Yuncong-Li and Teresa Olczyk ${ }^{2}$

\section{Irrigation Management in South Florida: A Key Issue}

As urban pressures increase, water may become a scarce resource. Although in general growers identify flooding as the number one threat to agriculture in the Miami-Dade County area, there have been periodic water shortages. In spite of this, the high yields of the Biscayne shallow aquifer give the general perception among growers that water is not a limiting factor, but rather an endless one!

Over-irrigation is a potential problem in this area and may be explained as a response to the low waterholding capacity and excessive permeability of the rocky soils found in the south Miami-Dade County agricultural area.

Over-irrigation has other effects, mainly environmental ones related to water quality. Excessive application of water may cause leaching of agri-chemicals present in the soil. This is especially critical in an area surrounded by Everglades and
Biscayne National Parks. Water conservation is the best way to increase the water management efficiency of agriculture and reduce potential negative environmental impacts.

Irrigation management (scheduling) may be accomplished by a number of different methods that strive to keep the soil moisture within a target range. An excellent method consists of utilizing soil moisture monitoring devices in conjunction with rainfall records and knowledge of plant needs.

Classical soil monitoring devices such as tensiometers and modified gypsum blocks, are available along with new soil devices such as Time Domain Reflectometers (TDR) and dielectric probes. However, the rock-plowed soils of the Miami-Dade County agricultural area are specially challenging, since its very coarse nature can pose soil contact problems for some of the available soil moisture devices.

1. This document is ABE 333, one of a series of the Agricultural and Biological Engineering Department, Florida Cooperative Extension Service, Institute of Food and Agricultural Sciences, University of Florida. Original publication date: October 2002. Visit the EDIS Web Site at http://edis.ifas.ufl.edu. 2. Rafael Muñoz-Carpena, Assistant Professor, Hydrology \& Water Quality Specialist; TREC-IFAS, Homestead, FL. Agricultural and Biological Engineering. Yuncong-Li. Assistant Professor, Soils and Plant Nutrition Specialist; TREC-IFAS, Homestead. Soil and Water Science. Teresa Olczyk, Extension Agent, Commercial Ag./Vegetables, Miami-Dade Cooperative Extension

The use of trade names in this publication is solely for the purpose of providing specific information. UF/IFAS does not guarantee or warranty the products named, and references to them in this publication does not signify our approval to the exclusion of other products of suitable composition.

The Institute of Food and Agricultural Sciences is an equal opportunity/affirmative action employer authorized to provide research, educational information and other services only to individuals and institutions that function without regard to race, color, sex, age, handicap, or national origin. For information on obtaining other extension publications, contact your county Cooperative Extension Service office. Florida Cooperative Extension Service/Institute of Food and Agricultural Sciences/University of Florida/Christine Taylor Waddill, Dean. 


\section{Agricultural Soils in South Miami-Dade}

South Miami-Dade has three calcareous agricultural soil types (Krome, Chekika and Marl) with a wide range of physical conditions. Their main physical properties were determined at TREC-IFAS labs (see Table 1).

Krome has $51 \%$ coarse particles (gravel $>2 \mathrm{~mm}$ ), Chekika 46\%, while Marl has none. This together with the different texture of each soil translates into differences in water permeability, water-holding capacity, wetting and drying speed, and ability to make good contact with some soil moisture monitoring devices.

Suction curves for these soils (Figure 1) show their particular soil moisture characteristics relevant to managing crop irrigation in the agricultural area.

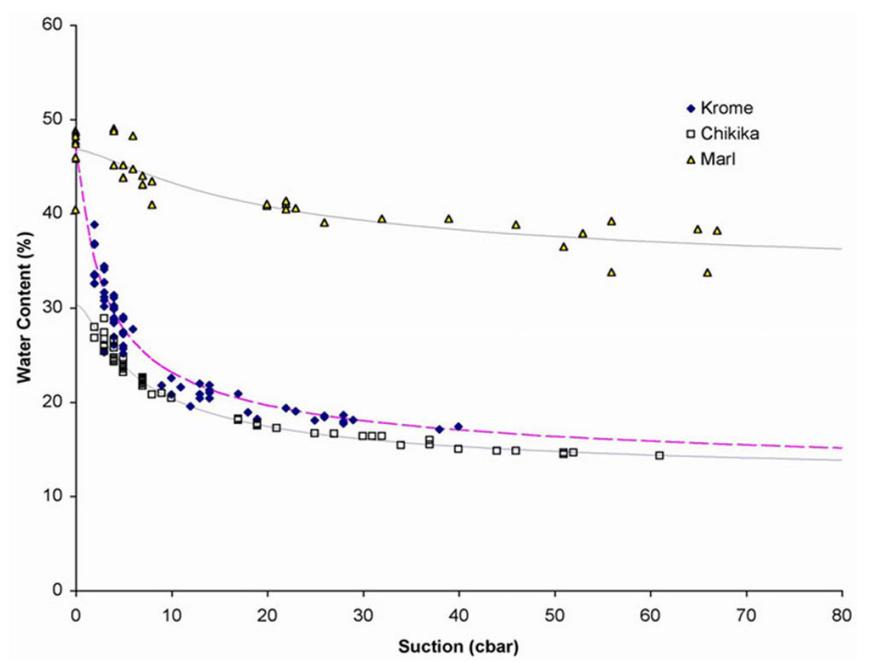

Figure 1. Soil water retention curves for each of the soils present in the Miami-Dade County agricultural area

Marl soils exhibit the typical behavior of a fine soil with large water holding capacity even at relatively high suctions.

The rock-plowed soils (Chekika and Krome) are made out of two distinct solid fractions: coarse gravel and fine loam (51\% and $49 \%$ respectively for Krome). Because of this, rock-plowed soils exhibit a peculiar soil moisture retention pattern where two soil moisture regions can be identified, each corresponding to one of the soil solid fractions (Figure 2).

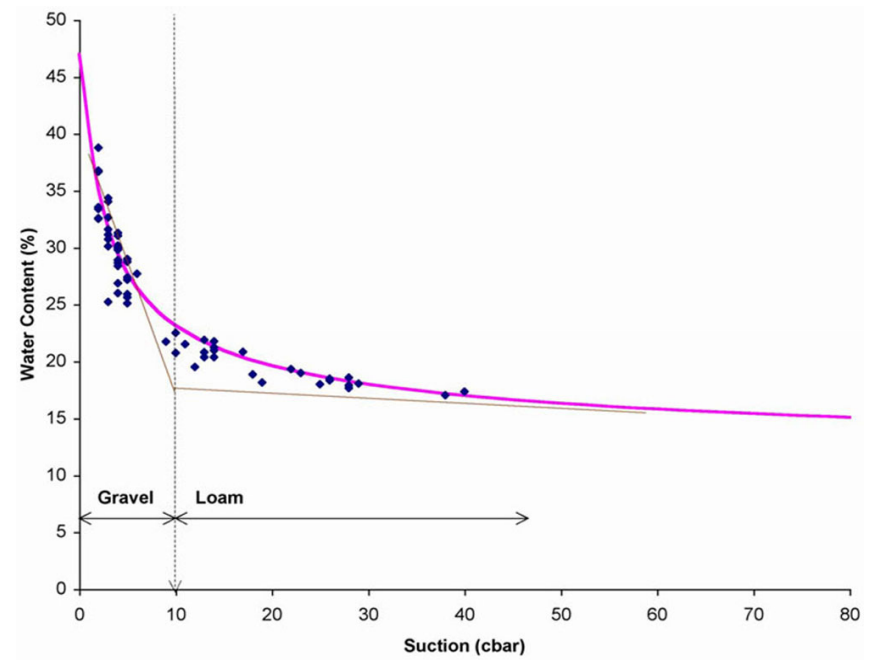

Figure 2. Effect of the gravel and loam soil fractions on Krome soil water retention

The soil moisture retention curves presented for the rock-plowed soils show that a large portion of water $(>50 \%)$ could be readily drained after irrigation if excess water is applied (gravel moisture region in Figure 2). Recognizing the existence of these two soil moisture regions is important not only in irrigation management and soil moisture measuring, but also in the assessment of potential agri-chemical leaching.

\section{How Do We Measure Moisture Content in Rock-plowed Soil?}

Moisture content is usually measured based on one of two quantities: volumetric water content [the amount of water per cubic unit of soil, common units are $\mathrm{cm}^{3} \mathrm{H}_{2} \mathrm{O} / \mathrm{cm}^{3}$ soil or \% when multiplied by 100] and soil suction or matrix potential [the amount of water held by capillarity against the force of gravity, often measured in units of pressure (i.e., cbar). These two quantities are related by the suction curves in Figure 1 and Figure 2. It is important to remember that each soil type (texture/structure) has a different soil moisture curve, so both quantities cannot be related to each other the same way for all soil types. The soil suction is a useful value since it relates to the energy that the plant has to expend to extract soil water.

Water Content. There are several alternatives for monitoring soil moisture, each with its "pros" and "cons". Issues involved are cost, accuracy, response time, preparation, installation, management, 
maintenance, and durability. Different technologies could prove advantageous in our range of calcareous soils, from the very permeable and coarse soils (Krome and Chekika) to the finer one (Marl).

Soil moisture (water content) can be measured directly by the gravimetric method. This entails sampling the soil with a core sampler, weighing the moist soil, then drying it in a oven, and then weighing the dry soil. However, this method is destructive (i.e., it is not possible to measure in the same location twice, and it does not yield instantaneous results).

We tested four different soil moisture sensors. Sensors were selected with a criterion of low cost $(<\$ 600)$ so that small producers with limited budgets could have access to any of them if they proved successful. Among these, two new low cost devices were selected (TDR and dielectric probe) and compared to two classic alternatives (tensiometers and modified gypsum blocks - also known as granular matrix sensors or GMS) (Figure 3).

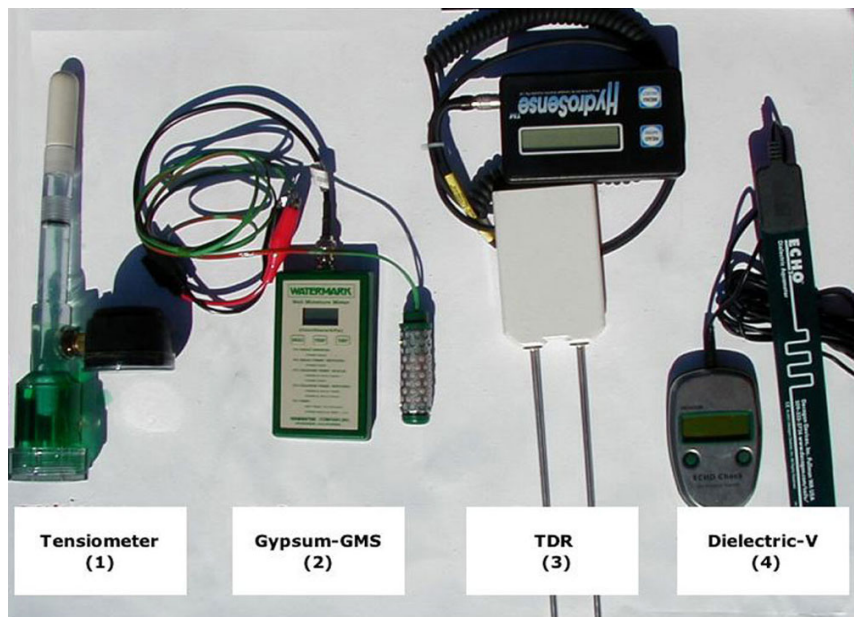

Figure 3. Soil moisture devices tested in Miami-Dade County agricultural soils

The probes were first compared side to side for each soil type in the laboratory. Each soil was hand-packed in PVC cylinders (Diam.10"xL8.5") according to its bulk density (Table 1), and the four sensors inserted. Three replicates for each soil type (Krome, Chekika, and Marl) were evaluated. All readings are compared to the gravimetric method as measured by weight on a laboratory scale. Results for the water content-based devices showed that TDR (3) can be used in all soil types with the standard calibration, where the dielectric probe (4) needs a specific calibration for each of the soils.

Soil Suction. Among suction-based devices, tensiometers lose soil contact and break the water column (i.e., requiring re-installation) at different suction levels (i.e., 40 cbar for Krome, 55 cbar for Chekika and >60 cbar for Marl). Therefore, under low frequency irrigation schedules, tensiometers could be of only limited use in Krome and Chekika soils because as the soil dries the water column within the device breaks. The gypsum block (2) showed a different response than that from tensiometers at high suction levels (drier soil). This could be a limiting factor if the sensor is to be used as a device to automatically switch off the irrigation unless the sensor is recalibrated. Calibration curves were obtained for all the sensors (gypsum blocks, TDR and dielectric probes) for each of the soils studied (see Factsheet ABE 334).

After obtaining this information a field test was conducted on a Krome soil since this soil is the most relevant soil in the region. Sensors were compared in a tomato field (drip irrigation, plastic mulch) at the University of Florida, IFAS, Tropical Research and Education Center. The irrigation treatment was based on a set maximum soil suction (tension) of 15 cbar. The four types of sensors were installed next to each other in the center of the tomato planting bed. Readings were taken daily at 8:30 am and 5:00 pm. Irrigation $(0.46 \mathrm{~cm})$ was applied at 11:00 am each day when needed (tensiometer readings higher that 15 cbar). The test began 7 March 2002 and irrigation stopped on 30 March 2002. Results are shown on Figure 4.

Through March 30 plant water demands were satisfied frequently and the moisture dielectric devices (TDR and dielectric probe) remained relatively unchanged during the normal irrigation period. However, when a large rainfall event occurred (see black bars in Fig. 4), there was a significant reaction by both water content-based probes. In general, both sensors gave also rather consistent readings with the moisture regime.

In contrast, suction devices capture not only rainfall but also irrigation and they are more sensitive in the field moisture range of 5-40 cbar. The 


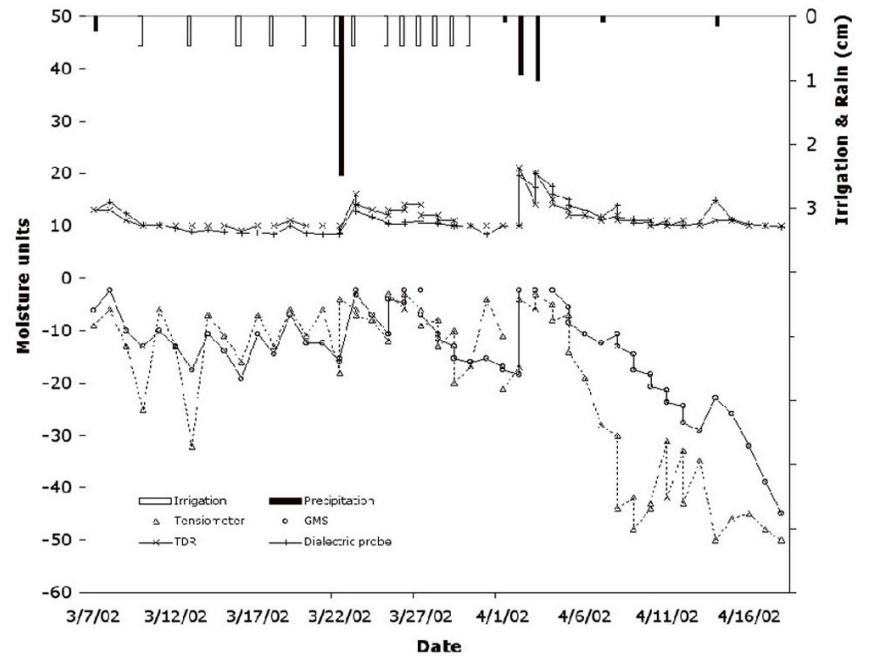

Figure 4. Field comparison of the soil moisture devices in a rock-plowed (Krome) soil under plasticulture (units are \% for TDR and dielectric probes; cbar for tensiometers and GMS)

sensitivity of tensiometers for the Krome moisture curve depends on the suction value (Figure 2). For suction levels $>10$ cbar the moisture content is relatively insensitive to suction changes. That is, large changes in suction translate into small changes in soil moisture content. This can be seen clearly in Figure 4 , where the large changes in suction values for the tensiometer and gypsum blocks correspond to small changes in the TDR and dielectric probe readings. This is not a factor of the instruments but of the peculiar soil water retention pattern of the rock-plowed soils.

The type of instrument to use in the rock-plowed soils could be conditioned by the irrigation regime. For low frequency irrigation (not recommended for rock-plowed soils), suction devices might be preferred since they will display changes clearly as the soil dries past the point in the soil water retention curve where water content readings are relatively insensitive. Care should be taken not to exceed the suction range at which the tensiometer discharge.

\section{Summary and Conclusions}

Each soil moisture monitoring device was evaluated based on the type of reading, cost of purchase, how involved the field installation was, ease of maintenance, how quickly it responded to changes in soil moisture, and whether it required calibration prior to installation (Table 2).
The disadvantages for each device are highlighted in grey background and underlined. Although the response varied in laboratory and field tests, all sensors gave consistent results for the soils found in south Miami-Dade County. Dielectric sensors require calibration for use in the rock-plowed soils present in this area.

\section{References}

Li, Yuncong. 2000. Using Tensiometers for irrigation Scheduling in Tropical Fruit Groves. Fact Sheet TR002. Fl. Coop. Extension Serv. IFAS, University of Florida, Gainsville.

Li, Yuncong. 2000. Irrigation Scheduling for Topical Fruit Groves in South Florida. Fact Sheet TR001. Fl. Coop. Extension Serv. IFAS, University of Florida, Gainsville.

Muñoz-Carpena, R., Yuncong-Li and Teresa Olczyk. 2002. Low cost soil moisture monitoring devices for vegetable production in the south Miami-Dade County agricultural area: Part 2Installation, Use and Maintenance. Fact Sheet ABE 334. Fl. Coop. Extension Serv. IFAS, University of Florida, Gainsville.

Olczyk, Teresa, Yuncong Li, and Rafael Muñoz-Carpena. 2002. Using Tensiometers for Vegetable Irrigation Scheduling in Miami-Dade County. Fact Sheet ABE326. Fl. Coop. Extension Serv. IFAS, University of Florida, Gainsville.

Simonne, Erik H., Michael D. Dukes and Dorota Z. Haman. 2001. Principles and Practices of Irrigation Management for Vegetables. Fact Sheet AE260. Fl. Coop. Extension Serv. IFAS, University of Florida, Gainsville.

Smajstrla, Allen G. and D.J. Pitts. 1997. Tensiometer Service, Testing and Calibration. Bull. 319. Fl. Coop. Extension Serv. IFAS, University of Florida, Gainsville.

Smajstrla, Allen G. and Dalton S. Harrison. 1998. Tensiometers for Soil Moisture Measurement and Irrigation Scheduling. Circ. 487. Fl. Coop. Extension Serv. IFAS, University of Florida, Gainsville. 
Zazueta, Fedro S. and Jiannong Xin. 1994. Soil

Moisture Sensor. Bull. 292. Fl. Coop. Extension

Serv. IFAS, University of Florida, Gainsville. 
Table 1. Physical properties of soils found in Miami-Dade County.

\begin{tabular}{llll}
\hline Property & Krome & Chekika & Marl \\
\hline Porosity & $45 \%$ & $47 \%$ & $65 \%$ \\
Bulk density $\mathrm{d}_{\mathrm{b}}\left(\mathrm{g} / \mathrm{cm}^{3}\right)$ & 1.42 & 1.33 & 0.94 \\
Coarse material $(>2 \mathrm{~mm}$ dia.) & $51 \%$ & $46 \%$ & $0 \%$ \\
Sand & $36 \%$ & $59 \%$ & $5 \%$ \\
Silt & $40 \%$ & $30 \%$ & $85 \%$ \\
Clay & $24 \%$ & $11 \%$ & $10 \%$ \\
USDA texture classification & Gravelly-loam & Gravelly-loamy-sand & Silt \\
Hydraulic conductivity, $\mathrm{K}_{s}$ & $317 \mathrm{~cm} / \mathrm{h}$ & $125 \mathrm{~cm} / \mathrm{h}$ & $9.15 \mathrm{~cm} / \mathrm{h}$ \\
\hline
\end{tabular}

Table 2. Summary of evaluation criteria for the soils sensors in Miami-Dade

\begin{tabular}{|l|l|l|l|l|}
\hline & Tensiometer & \multicolumn{1}{|c|}{ GMS } & Dielectric & \multicolumn{1}{|c|}{ TDR } \\
\hline Reading & Direct-suction & $\begin{array}{l}\text { Indirect-suction } \\
\text { (electrical } \\
\text { resistance) }\end{array}$ & $\begin{array}{l}\text { Indirect-water } \\
\text { content } \\
\text { (Dielectric- } \\
\text { voltage) }\end{array}$ & $\begin{array}{l}\text { Indirect-water } \\
\text { content } \\
\text { (Dielectric-time) }\end{array}$ \\
\hline Cost & $\$ 70-110$ & $\begin{array}{l}\text { Probe } \$ 30 \\
\text { Reader } \$ 250\end{array}$ & $\begin{array}{l}\text { Probe } \$ 100 \\
\text { Reader } \$ 375\end{array}$ & $\begin{array}{l}\text { Probe } \$ 260 \\
\text { Reader } \$ 325\end{array}$ \\
\hline Set-up & Involved & Minor & Minimal & Minimal \\
\hline Maintenance & Yes-important & No & No & No \\
\hline Response & Fast & $\frac{\text { Differs from }}{\text { tensiometer at }}$ & Instantaneous & Instantaneous \\
\hline Calibh suction & $\underline{\text { Yes }}$ & $\underline{\text { Yes }}$ & $\begin{array}{l}\text { No (only for } \\
\text { research) }\end{array}$ \\
\hline
\end{tabular}

